\title{
Automated Construction System for High-rise Reinforced Concrete Buildings
}

\author{
Tatsuya Wakisaka, Noriyuki Furuya, Kyoichi Hishikawa, \\ Yasuo Inoue, Takashi Shiokawa, Kyoji Yoshino, \\ Koji Hamada, Fumihiro Inoue, Kohei Kurita \\ Technical Research Institute of Obayashi Corporation, \\ 4-640 Shimokiyoto, Kiyose-shi Tokyo 204, JAPAN
}

\begin{abstract}
The all-weather automated construction system has been developed to reduce the total cost of high-rise reinforced concrete building construction, and was applied to a 26-story reinforced concrete condominium project located in Chiba prefecture in 1995 for the first time in the world. This automated construction system consists of four major technologies: a) Synchronously climbing allweather temporary roof; b) Parallel material delivery system with one construction lift and three overhead cranes carrying three transfer hoists; c) Prefabrication and unification of construction materials; and d) Material management system using database system linking with $C A D$.

Consequently this automated system is effective when used at the site. It ensures good quality, improves the working and environmental conditions, reduces the construction period, manpower, and wastes, and improves overall productivity.
\end{abstract}

\section{Introduction}

In Japan, the lack of and aging of skilled construction laborers have been steadily worsening. In order to solve this problem, we need to raise productivity significantly and to improve the terms of employment and working conditions to attract young laborers. Obayashi Corporation has developed a new building construction system that improves productivity greatly. The automated construction system for high-rise reinforced concrete buildings is a part of this new system.

The basic principle of this system is to integrate techniques such as all-weather, mechanization and automation, prefabrication and unification, and the use of information to build the most suitable automated system for tall reinforced concrete apartment houses that are in demand in urban regions. It is difficult to raise the level of automation for reinforced concrete structures compared with steel structures in terms of cost and effect. An all-weather assembly plant can easily be set on a steel structure using ABCS (automated building construction system, developed by Obayashi Corporation in 1989)[1], but it would be difficult to do with a reinforced concrete structure because the concrete must be left to harden.

We developed and applied an automated system aiming at CAD/CAM for complicated reinforcement work in a 41-story reinforced concrete apartment house construction from 1988 to 1990[2]. Automation at the work level (a part of the construction process) did not improve productivity sufficiently and greater automation and systematization at the project level (the whole process) were required. So we began to develop an automated construction system for high-rise reinforced concrete buildings in 1991 and as a result of feasibility studies for some proposals, we chose the optimal system for practical use in 1994 and used it to build a 26-story reinforced concrete apartment house in Tokyo Metropolitan area in 1995 for the first time in the world (Figure 1). This system is called BIG CANOPY (Big Canopy

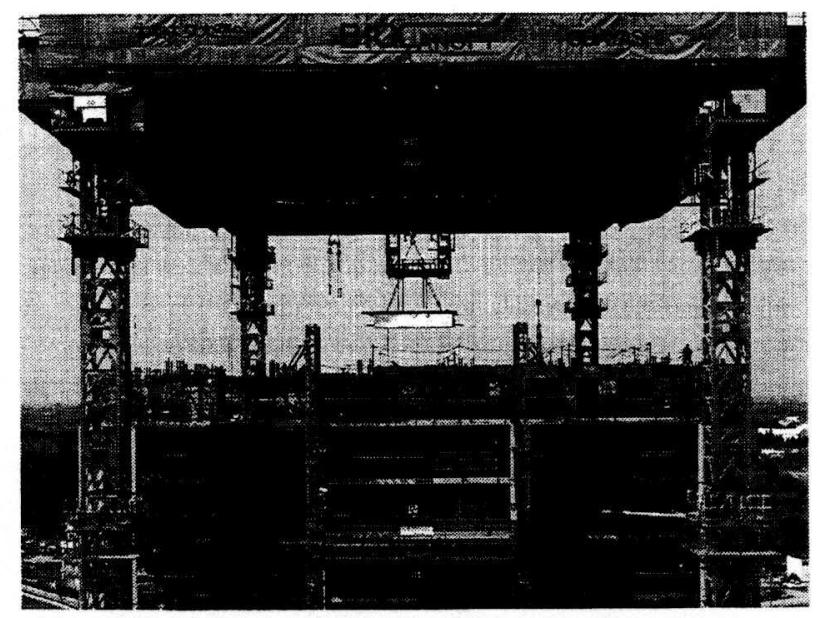

Figure 1: Whole view of BIG CANOPY 
automation system for high-rise reinforced concrete buildings) and is described in the following.

\section{Outline of BIG CANOPY}

\subsection{Main features of the system}

In BIG CANOPY, we set a parallel material delivery system with automated overhead cranes and one large construction lift under an all-weather synchronously climbing temporary roof frame, and used versatile, all-round workers, extensive prefabrication and unification of construction materials, and a material management system using a database linked with the CAD system. The main features are as follows:

(1) Improvement of productivity: The overhead crane is superior in operability compared with the tower crane, and the parallel delivery system increases the efficiency of delivery and erection, and versatile workers can cooperate without wasting time.

(2) Stability of quality: Quality is stabilized by prefabrication and unification, and the all-weather temporary roof.

(3) Short construction period: The period is shortened by the use of prefabrication and unification, stable processing by all-weather construction, and early commencement of the interior finishing work.

(4) High degree of design freedom: As temporary posts are independent of the building, we can flexibly apply the system to various building shapes. According to some statistical data, this system can be applied to about $80 \%$ of high-rise reinforced concrete buildings.

(5) Improvement of construction environment: Severe heat, wind and rain are moderated, and workers can work safely and comfortably under the temporary roof.

(6) Safety to perimeter: The area of activity is compact, and safety of the neighborhood is high.

(7) Reduction of debris: Prefabrication and unification reduce debris.

(8) Reduction of total cost: The above (1) (7) reduce overall cost.

\subsection{Synchronously climbing temporary roof}

The synchronously climbing temporary roof consists of four tower crane posts erected independently outside of the building, climbing equipment, and temporary roof frame. We developed a new synchronously climbing jack system to keep the roof level when moving up and down. Figure 2 shows the control monitor. The roof is raised two

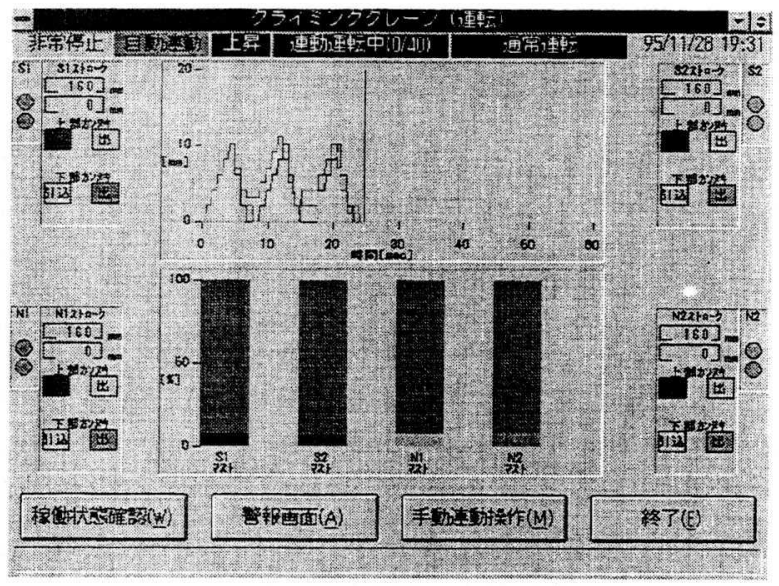

Figure 2: Control monitor of synchronously climbing equipment

floors at a time. The up and down movement speed of equipment is $300 \mathrm{~mm} / \mathrm{min}$, and each $6-\mathrm{m}$ climb takes slightly less than one hour.

The temporary roof is a shingle roof with folded thin steel plates on a steel frame truss structure and is about $50 \mathrm{~m}$ square. The entire weight including the roof frame, climbing equipment, overhead cranes and jib-crane is about $600 \mathrm{t}$. The jib-crane set on the temporary roof was used for adding posts after climbing and for dismantling the temporary roof frame.

\subsection{Parallel delivery system}

The parallel delivery system consists of a construction lift and three overhead cranes (Figure 3 ). The central overhead crane (delivery crane) removes a load from the lift and the right or left crane (erection crane) receives the hoist with a load from the delivery crane and erects it. These machinery reduce the waiting time of both workers and machines, and achieve efficient delivery and erection by simultaneous operation.

Before deciding the specifications of the parallel delivery system, we examined the cycle time of each precast concrete (PC) member erection and line balance of a lift and cranes by using a simulator on a personal computer (Figure4).

Hoist exchange between the delivery crane and erection crane is performed as shown in Figure 5. This system is mostly manual, but the traveling of the delivery crane and crane girder positioning between the delivery crane and erection crane are automated to reduce the work load on the operator. We introduced a suspender device to control load rotation by gyroscopic moment to prevent 


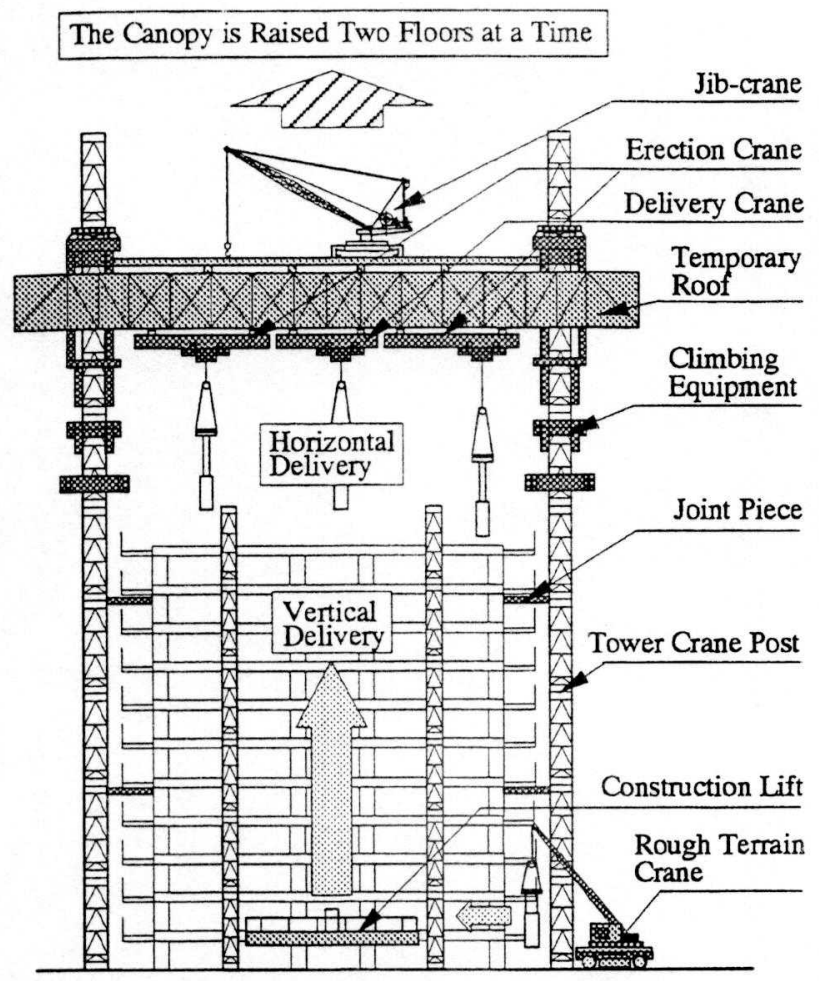

Figure 3: Parallel delivery system

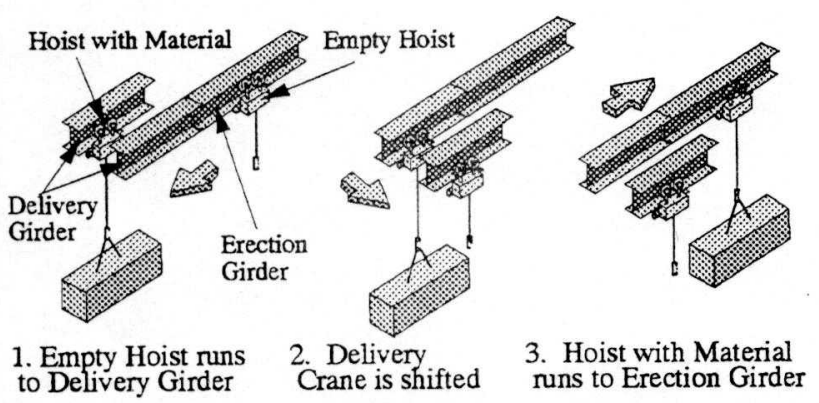

Figure 5: Hoist exchange system

interference during hoist exchange. The major specifications of the parallel delivery system are shown in Table 1.

Members are delivered in the following order from ground to erection location.

(1) The rough terrain crane discharges members carried to the site and loads them onto the lift.

(2) The lift conveys them to the erection floor.

(3) The delivery crane removes them from the lift.

(4) The delivery crane runs to the waiting erection crane and stops at the correct position.

(5) The exchange of hoists is done between the delivery crane and erection crane. Then the delivery crane runs back to the lift top and the loaded hoist traverses to the erection point.

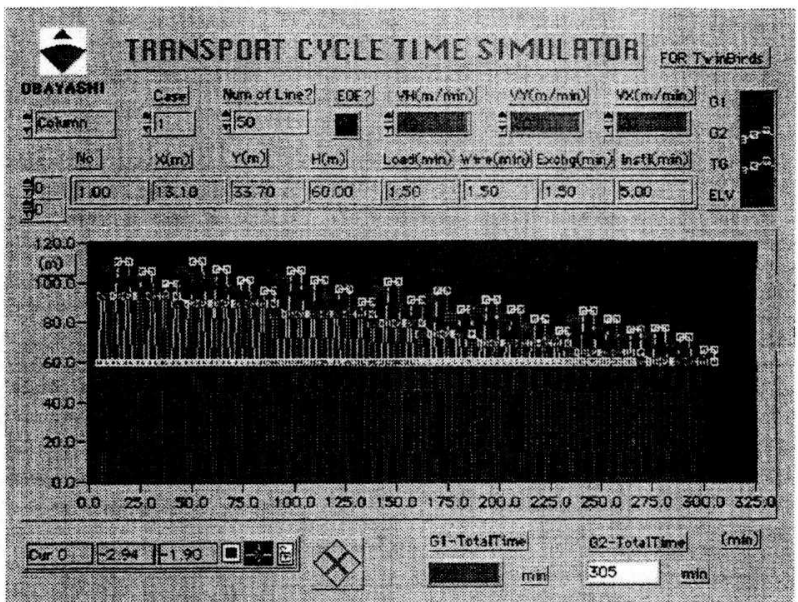

Figure 4: Transport cycle time simulator

Table 1: Specifications of parallel delivery system

\begin{tabular}{|c|c|}
\hline $\begin{array}{l}\text { Name and Number } \\
\text { of Device }\end{array}$ & Specification \\
\hline $\begin{array}{l}\text { Construction } \\
\text { Lift }\end{array}$ & $\begin{array}{l}\text { Loading Capacity : } 6 \mathrm{t} \\
\text { Winching up Speed }: 40 \mathrm{~m} / \mathrm{min} \\
\text { Control Type:Invertor }\end{array}$ \\
\hline $\begin{array}{l}\text { Hoist Exchanging } \\
\text { Overhead Crane }\end{array}$ & $\begin{array}{l}\text { Operation Type :Manual/Automatic } \\
\text { Wireless Remote Control } \\
\text { Control Type :Invertor }\end{array}$ \\
\hline Delivery Crane 1 & $\begin{array}{l}\text { Maximum Traveling Speed }: 40 \mathrm{~m} / \mathrm{min} \\
\text { Suspended Capacity }: 7.5 \mathrm{t}\end{array}$ \\
\hline Erection Crane 2 & $\begin{array}{l}\text { Maximum Traveling Speed }: 30 \mathrm{~m} / \mathrm{min} \\
\text { Suspended Capacity }: 7.5 \mathrm{t}\end{array}$ \\
\hline Electric Hoist 3 & $\begin{array}{l}\text { Maximum Traversing Speed }: 33 \mathrm{~m} / \mathrm{min} \\
\text { Suspended Capacity }: 7.5 \mathrm{t}\end{array}$ \\
\hline $\begin{array}{l}\text { Jyroscopic } \\
\text { Suspender }\end{array}$ & $\begin{array}{l}\text { Operation Type :Wireless Remote Control } \\
\text { Weight:1100kg } \\
\text { Rotating Drive:Jyroscopic Moment } \\
\text { Inertia Moment of Load:25ton m } 2\end{array}$ \\
\hline
\end{tabular}

\subsection{Material management system}

The concept of the material management system is shown in Figure 6. The material management database which links up with CAD shop drawings is used to rationalize the planning from material delivery to erection and the actual management. The material management is unified by using bar codes attached to the materials at the factory. Figure 7 shows a worker reading the bar code of a girder by using a portable terminal. A screen display used to monitor the state of progress of $\mathrm{PC}$ member erection is shown in Figure 8. The manager is able to accomplish various kinds of material management effectively by utilizing CAD. 


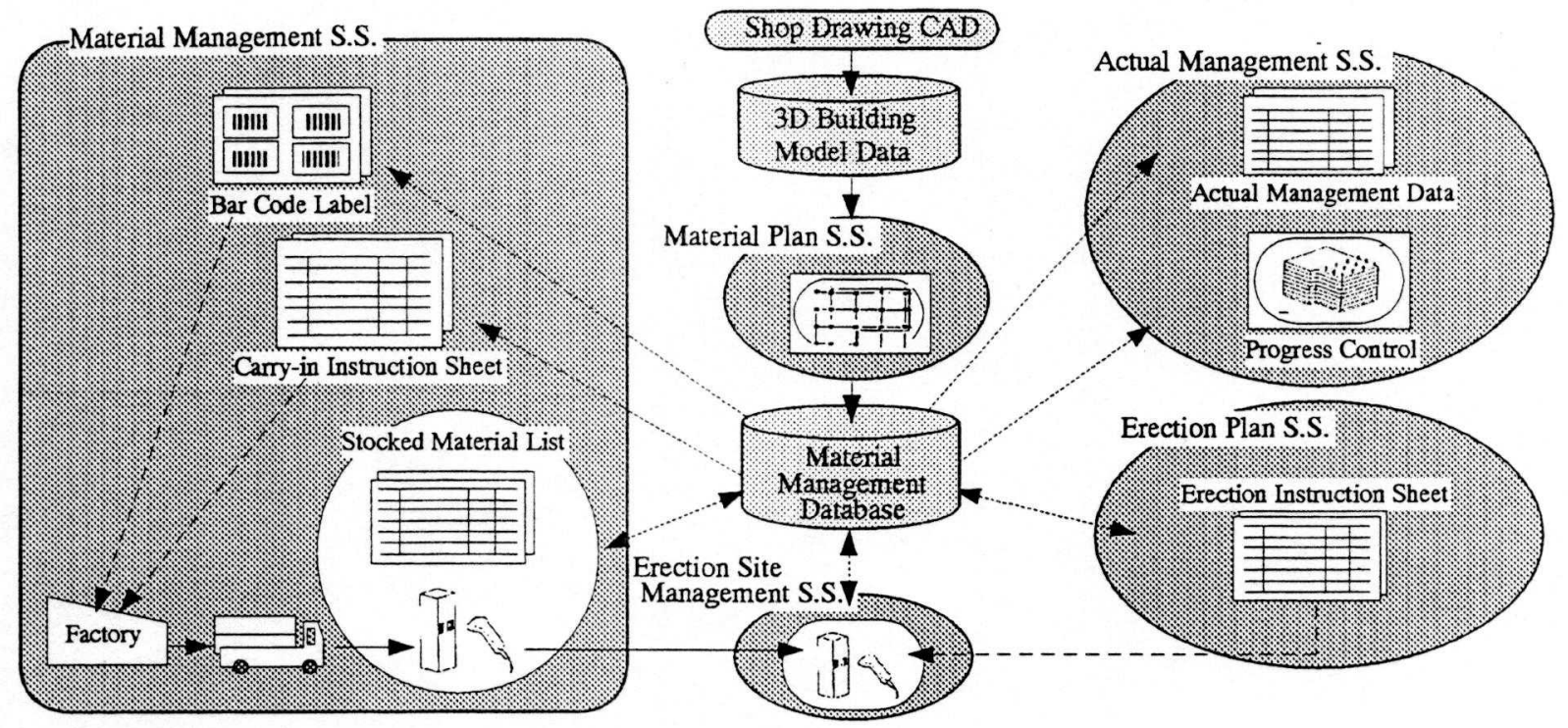

Figure 6: Material management system

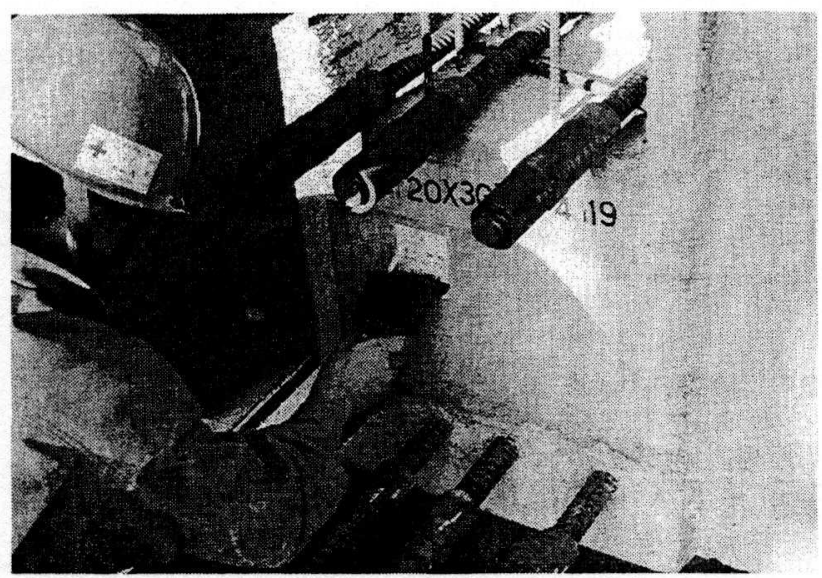

Figure 7: Reading a bar code

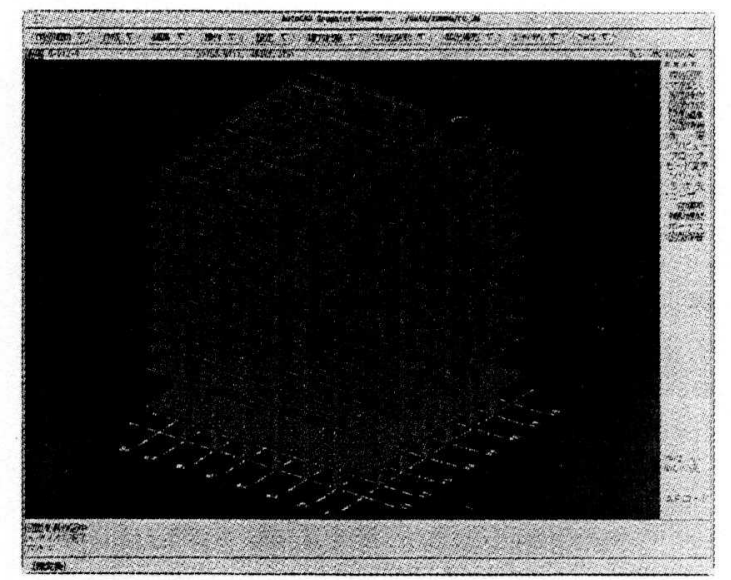

Figure 8: Progress control of PC member erection

corridor.

A constant number of versatile workers is used for many kinds of works related to the skeleton, finishing and equipment of the erection floor every day.

\subsection{Prefabrication and unification}

We adopted the industrialized construction method using many PC members higher than the third floor, the cross section of the skeleton of which was standardized. Column, wall and balcony are full PC members, and girder and slab are half PC members (Figure 9). Concrete was placed in panel zones and the upper part of girders and slabs at the site. The rate of prefabrication was $71 \%$ of concrete volume, $97 \%$ of form area, and $79 \%$ of bar weight, which are extremely high ratios. We adopted grout 

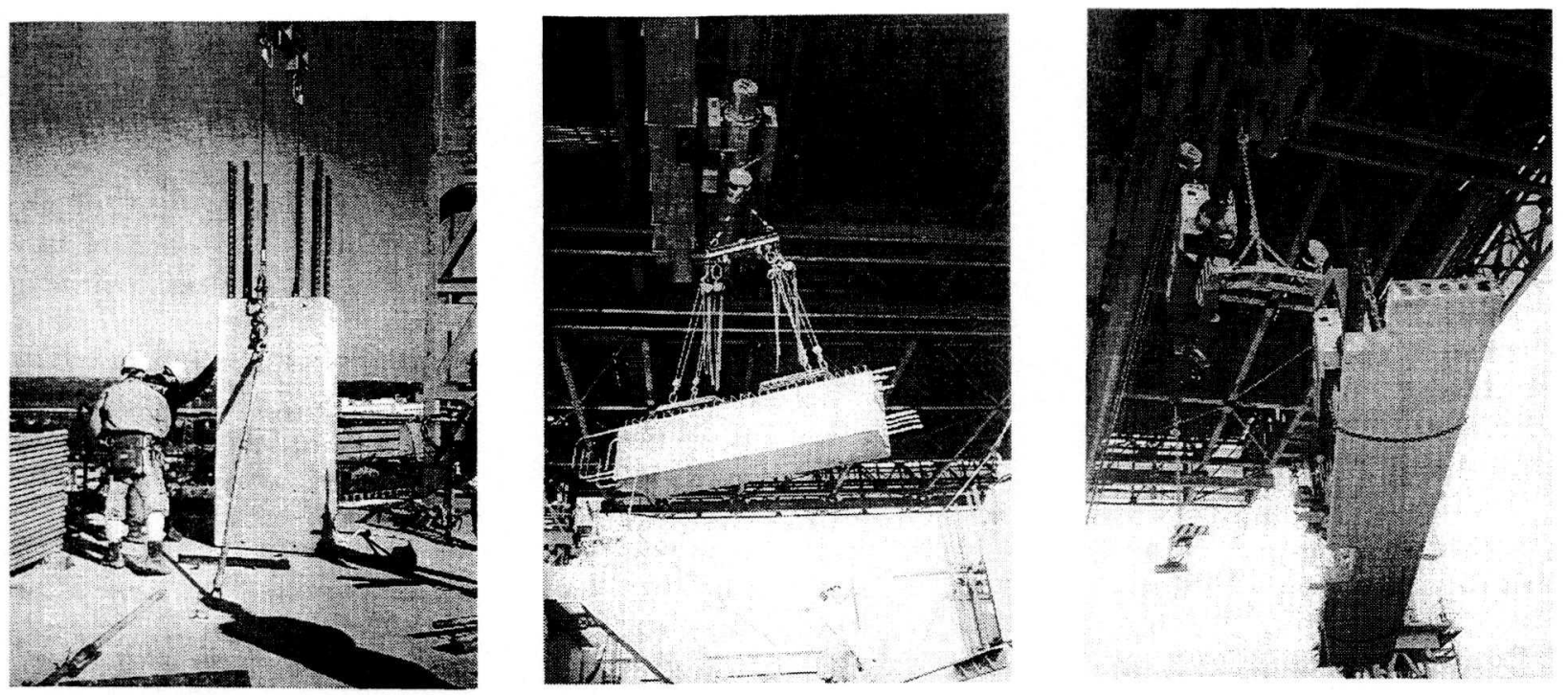

Figure 9: Erection PC members

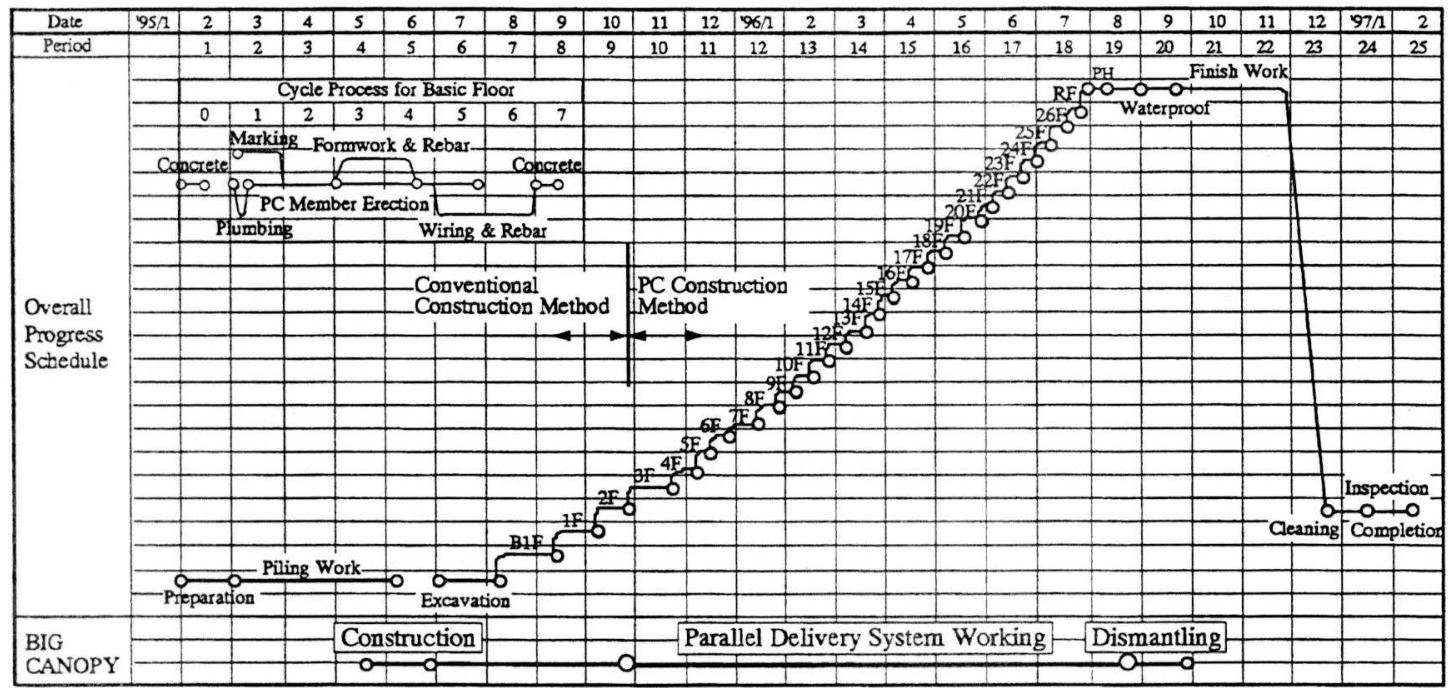

Figure 10: Overall progress schedule and cycle process for basic floor
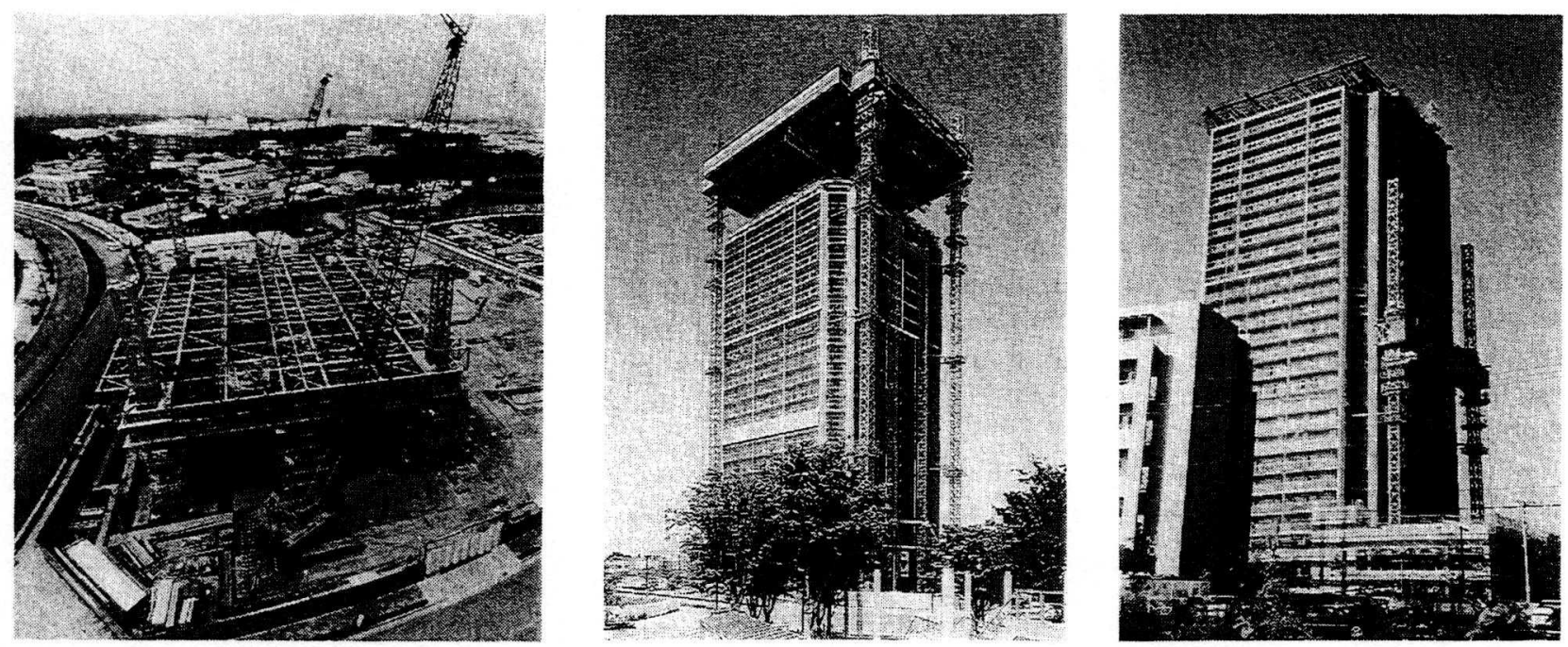

Figure 11: From construction of temporary roof to dismantling it 
connection through sleeves in jointing column bars and joined screw bars with a coupler in panel zones in connecting girders.

As for the finishing and equipment work, we unified the pipes around the meter boxes, vertical drainpipes, indoor low current cables and low current main line cables; prefabricated the horizontal drainpipes and air conditioning ducts of each apartment; and precut the ALC panels, boundary wall panels and wooden axis partition to save manpower and reduce waste. In particular, we set vertical drainpipes simultaneously with the skeleton work to plug the holes in the construction floor and prevent water flow.

\subsection{Construction process}

The overall progress schedule with the cycle process of the basic floor is shown in Figure 10. The progress from construction of the temporary roof to dismantling it is shown in Figure 11.

Construction of the temporary roof took about one month, in May, 1995, after piling work, and then basement excavation work was done under the roof. Overhead cranes were installed simultaneously with construction of the first floor using the conventional method, and the whole system began to work from the end of October, 1995 when the PC construction method started. From August, 1996 when the skeleton work was completed, we lowered the temporary roof on the building roof and dismantled the central part with a jib-crane, took down the perimeter part by reversing the sequence of climbing, and dismantled it on the ground.

The cycle time of the basic floor was seven days and the shortest was six days. In winter when concrete was slow to harden, it took eight days.

\section{Effect of applying BIG CANOPY}

\subsection{Improvement of work environment}

Figure 12 shows measurements of the surface temperature of workers' clothes and material (steel bars) under the temporary roof and outdoors in fine weather in the summer. There were differences of about $10^{\circ} \mathrm{C}$ maximum with workers' clothes and about $25^{\circ} \mathrm{C}$ maximum with bars between under the temporary roof and outside.

In outdoor work, workers' measured heart-rate was 134 beats/min at maximum with a mean value of 103 beats $/ \mathrm{min}$, and was about $80 \%$ and $40 \%$ higher compared with that at rest measured in the lunch break. On the other hand, when working under the temporary roof, the heart-rate was 108 beats/ min at maximum with a mean value 89 beats/min, and was about $45 \%$ and $20 \%$ higher compared with that at rest. The temporary roof thus significantly reduced the physical load on workers. A questionnaire survey showed strong approval of the temporary roof; work efficiency deteriorates as temperature rises when working in a hot environment.

There were 66 days when the temperature during activity time exceeded $30^{\circ} \mathrm{C}$ of the 123 days from July to September in 1995 and in July, 1996. The decline of productivity is equivalent to 50 hours (6.3 days) of lost time[3]. It is thought that there is about a $10 \%$ reduction in productivity in the hot summer, but under the temporary roof there was almost no degradation of work efficiency.

The effect of wind velocity during the PC construction period (from November, 1995 to July, 1996) is shown in Figure 13. The total time when the mean wind velocity exceeded $10 \mathrm{~m} / \mathrm{sec}$ on the roof during activity time was 87 hours, hence there

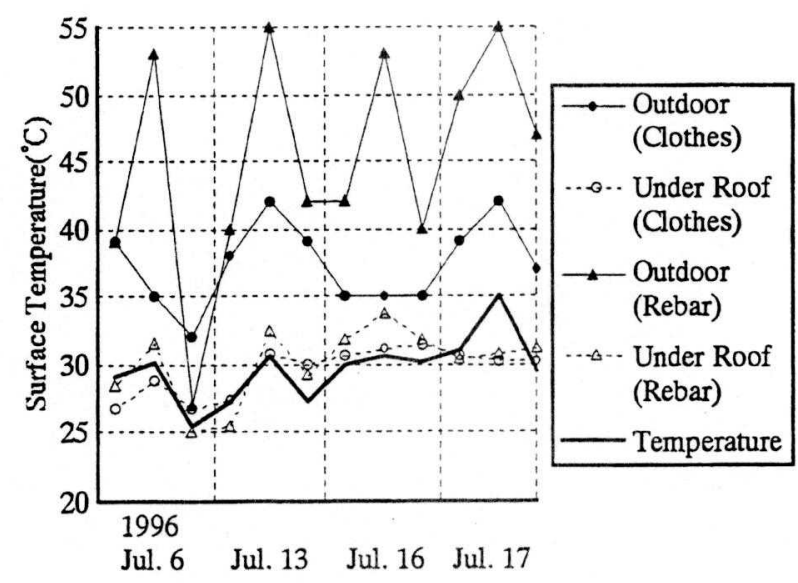

Figure 12: Surface temperature of workers' clothes and steel bar

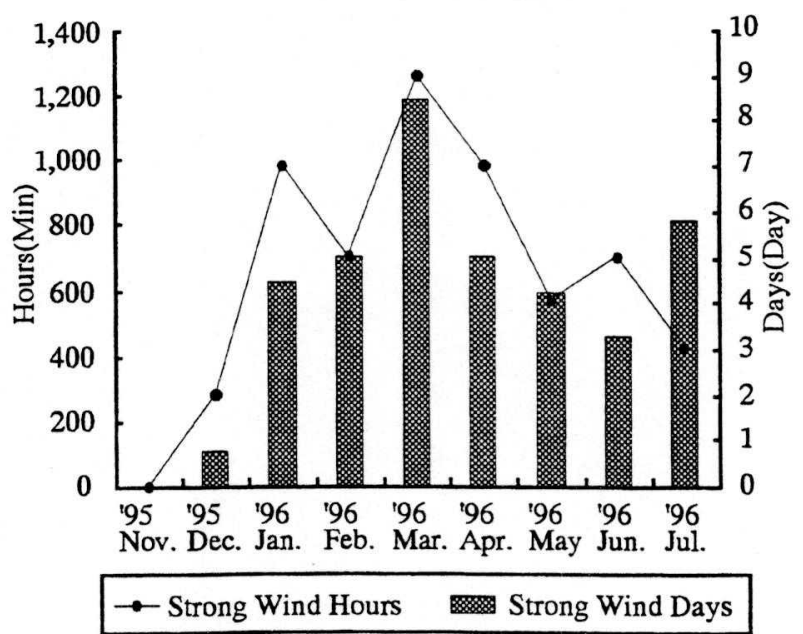

Figure 13: Strong wind effect 
were about 12 days when tower crane work was impossible, but only 1.5 days were interrupted in this system. The cause is thought to be as follows: the wind velocity is reduced to around $2 / 3$ under the temporary roof; vertical delivery is done by the lift; and as the wire length was short, load swing caused by the wind is small.

\subsection{Improvement of productivity}

At first two tower cranes (200tm) were planned to be used in this construction. Using the results of work measurement, we compared the erection time of PC members and found that the capability of the parallel delivery system is equal to about 2.5 tower cranes (Figure 14). Efficiency is improved because: the parallel delivery system is effective; overhead cranes are little affected by wind; and the operator can operate the crane while grasping the erection situation precisely.

The analysis of the learning effect for each activity is shown in Figure 15 and 16.The learning rate of total activity is about $87 \%$ and there are some activities less than $85 \%$, so the learning effect was high. The total number of laborers on the fourth floor at the beginning was many, but that on the 25 th floor was reduced to $36 \%$.

Labor productivity of skeleton work is compared among four kinds of construction methods for highrise buildings in Figure 17. The four kinds of construction method are: a) the conventional method of construction, b) system form method of construction in which PC slabs are used, c)construction method using PC members with tower crane, and d) BIG CANOPY. The number of workers engaged in skeleton work of BIG CANOPY was about $25 \%$ of the conventional method of construction, about $35 \%$ of the system form method of construction and about $65 \%$ of the PC method of construction. Labor is saved by the simplification and standardization of work by prefabrication, and the reduction of waiting time by the effective delivery system and use of versatile workers.

We did not use the complete automated erection system of $A B C S$ due to cost and effect. This time we automated only exchanging of the hoist for the overhead crane. We conducted an experiment to widen the scope of automation, with the delivery crane removing the load from the lift, moving to the erection crane with a loaded hoist, and returning to the lift top after exchanging hoists (Figure 18). As a result, the time of one cycle of automatic control was about $5 \%$ more than that of manual control, but we could reduce one operator. Complete automation is technically possible if we combine this upgraded system with the material management

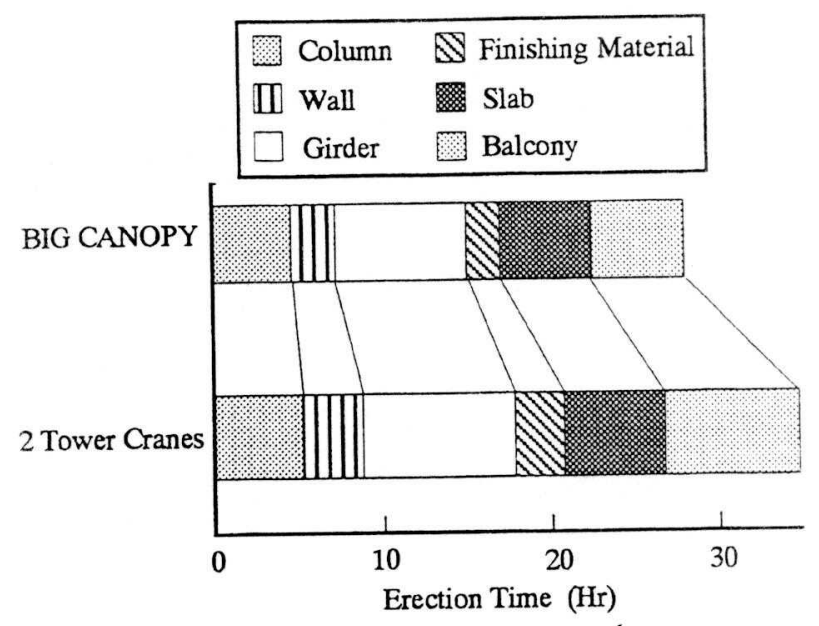

Figure 14: Efficiency comparison between two tower cranes and parallel delivery system

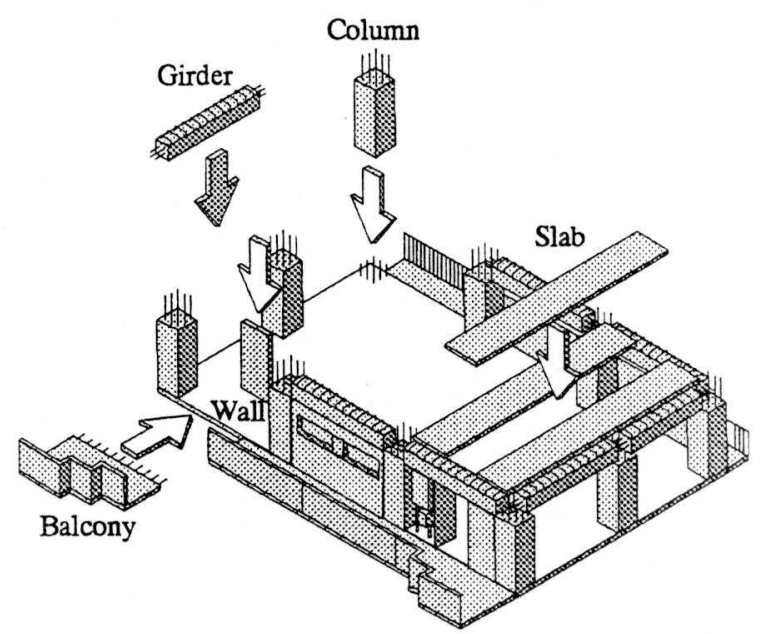

Figure 15: Main activity of PC construction

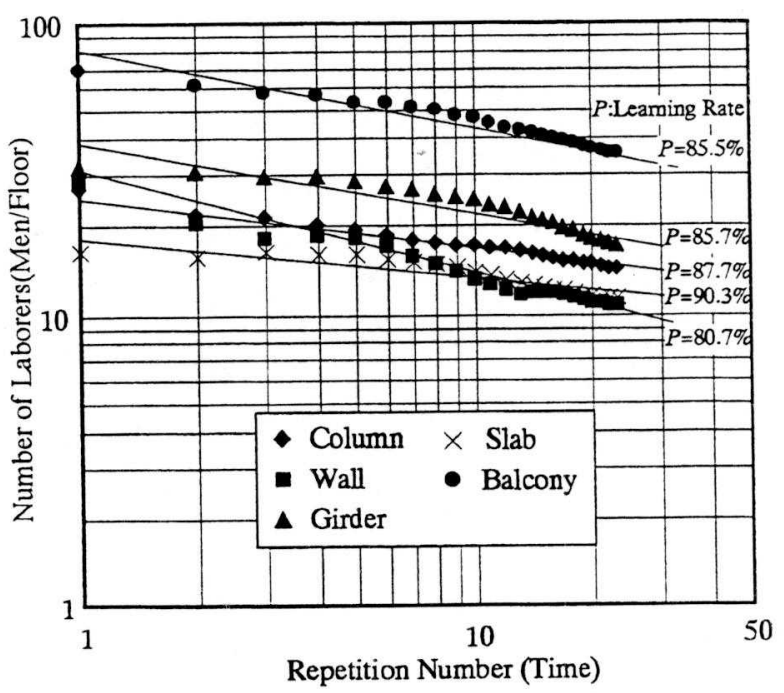

Figure 16: Learning effect 


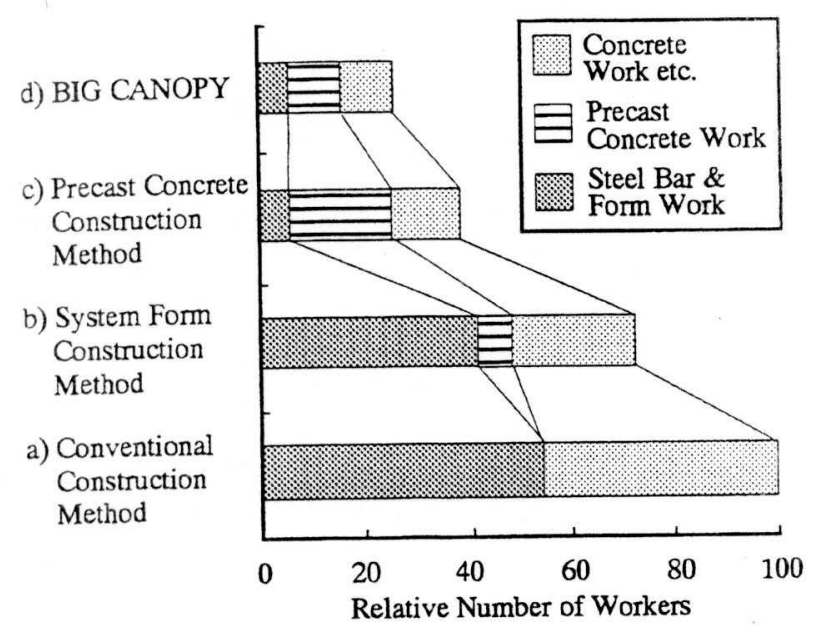

Figure 17: Productivity comparison among four construction methods

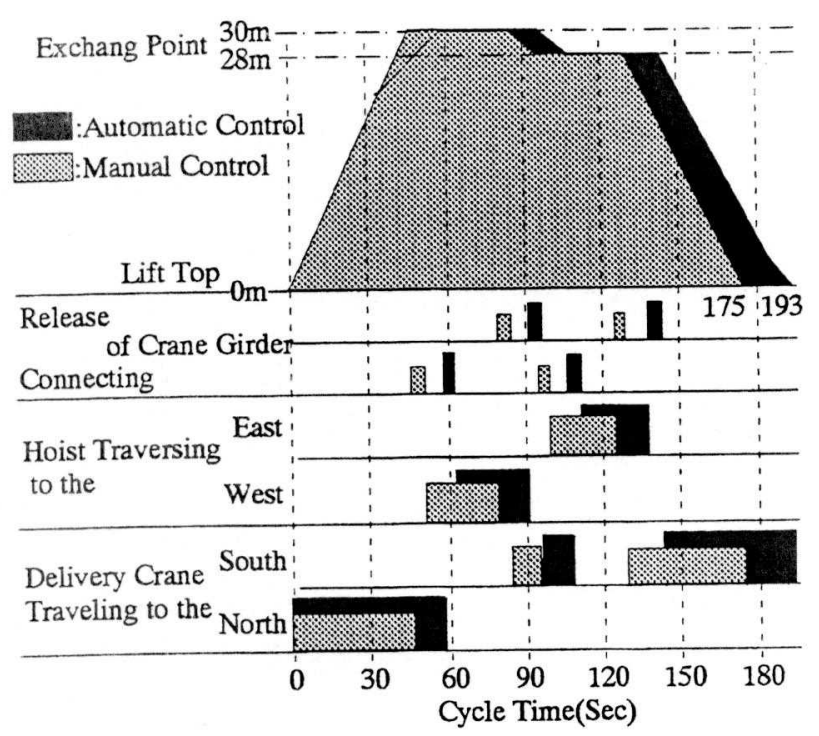

Figure 18: Automation Experiment of overhead cranes system using bar codes.

\subsection{Shortening of construction period}

Skeleton work was interrupted by one month to erect the temporary roof, but there was no interruption of activity by weather. As the temporary roof stabilized the skeleton work and allowed the finishing work to start early, the expected construction period for works by two tower cranes ( 28 months) was reduced by four months.

\section{Conclusion}

BIG CANOPY is used mainly for the construction of high-rise reinforced concrete apartment buildings. However, there is the constraint that temporary construction costs must not increase greatly because of the low construction unit cost of reinforced concrete buildings. Accordingly, in our development we utilized the construction equipment that we possessed and reduced the development cost by using general-purpose equipment in the market as much as possible. We chose the optimal automation level of the system so that workers could use their skills, and examined the balance of cost and effect. We achieved very high productivity and reduced the construction period without increasing construction cost. This system increases the level of automation, adds a new function and is flexible according to the situation. BIG CANOPY is thus viable and has a bright future.

\section{Acknowledgment}

Finally, we express our gratitude to the members who cooperated with the development of this system. Gratitude is also expressed to Minoru Yosida, general manager and the members of the construction site office.

\section{References}

[1] Kudoh R., "Implementation of an Automated Building Construction System", Proc. of 13 th International CIB World Building Congress, 1995,pp17-28

[2] Wakisaka T. et al., "Automatisation of Reinforcement Work in High-rise Reinforced Concrete Buildings", Proc. of 7 th ISARC, 1990, pp 79-86

[3] Koeehn E. et al., "Climatic Effects on Construction", Proc. ASCE, Vol. 111, No.2, 1985, pp129-137 